\title{
Understanding Consumer Choices and Preferences in Transaction-Based e-Services
}

\author{
Zafar Iqbal, DePaul University \\ Rohit Verma, University of Utah \\ Roger Baran, DePaul University
}

\begin{abstract}
The rapid increase in transaction-based e-services creates a challenge for firms: What combination of features should they offer to satisfy consumers while realistically considering operational and financial constraints? This article explores the above question by highlighting similarities and differences in consumer preferences between different segments for a transaction-based e-service. The study employs a Web-based discrete choice experiment, in which 1,430 consumers are offered e-service options, differing from each other in terms of non-web-based and online-only features, price per transaction, and marketing promotions. The results demonstrate that overall, consumer preferences for features of transaction-based e-services differ between offline and online consumers. Furthermore, with increase in consumer usage frequency, interesting trends regarding the relative importance for features are observed. Similarities also exist in consumer preferences between various usage-frequency-based consumer segments. The authors believe that these results have both managerial and research implications for design and operations strategy formulation for transaction-based e-services.
\end{abstract}

\section{Introduction}

Despite continuing failures of many dot.com firms, the use of e-services is projected to increase at a rapid rate. Sales using transaction-based e-services, defined as those enabling online sales of products with a price paid per transaction, are also predicted to rise significantly. For example, online sales of financial products, software, air travel, PCs and peripherals, books, music, tickets, car rentals, games, and videos are all predicted to increase substantially within a 3-year time frame (Timmons 2000; "The Web's Top Sellers" 2000). However, Rust, Lemon, and Zeithaml (2001) reported that more than $\$ 6.1$ billion in potentialWeb sales were lost during 1999 because of inadequate e-service offerings. They suggest that to be effective and successful, e-services need to understand new consumer needs such as offering a better purchasing experience, greater consumer control, and better personalization options. Preliminary support for the relative importance of various Web-based features is also highlighted by a recent empirical study by Koufaris (2002). Similarly, Torkzadeh and Dhillon 
(2002) identified that shopping convenience, consumer relations, Internet ecology, and value of the product offerings influence success of an Internet-based business. Specifically looking at technical features, Palmer (2002) found that not all technical aspects of a Web site are equally associated with the success of an online business. Thus, there is a need to understand how consumers make trade-offs between various features when choosing a transaction-based eservice.

Studying transaction-based e-services is also important because ever since the early days of e-commerce, scholars have argued that e-services, compared with offline services, have the ability to serve consumers more efficiently, at a lower marginal cost, while simultaneously offering real-time product- and/or service-specific information (Evans and Wurster 1999; Shapiro and Varian 1999). In addition, it is argued that by using monitoring software and consumer relationship management techniques, e-service firms can track, analyze, and cater to specific consumer needs (Peppers, Rogers, and Dorf, 1999). However, although there are many benefits of Web-based tools and technologies, we also need to recognize the costs associated with developing and delivering e-services. Given that firms have limited capital and other resources, managers need to understand the relative benefits of various online only and traditional (non-Web-based) features of their e-service offerings for the targeted set of consumer segments. In other words, to be successful, e-services need to identify and focus on developing features that enhance consumer value and not waste capital and resources on features that consumers do not prefer (e.g., Han and Han 2002; Parasuraman 1997; Woodruff 1997; Xue, Harker, and Heim 2000).

Although researchers have been actively studying various aspects of e-commerce, key questions related to the design of e-services still remain unanswered (e.g., Rust and Lemon 2001).We seek to explore some of these open issues in order to help firms achieve success in designing transaction-based e-services that are combinations of traditional (non-Web-based) and online-only features. Specifically, in this article, we aim to achieve the following objectives:

Objective 1: Demonstrate how consumers trade off between traditional (non-Web or offline) features and online-only features when choosing transaction based eservices.

Objective 2: Study whether the relative utilities of traditional (non-Web) features, online-only features, brick-and-mortar backup, and marketing promotions differ between consumers who vary in their familiarity with transaction-based eservices.

Objective 3: Study whether price sensitivities differ (a) between offline and online consumers and (b) as consumers become more familiar with, or increase, the usage of transaction-based e-services.

We believe that pursuing the above objectives will add to scholarly knowledge and will also assist managers in designing more effective e-service offerings. The rest of the article is 
organized as follows: First, we review the related literature in e-service design, consumer choice, marketing, and operations strategy; second, we describe the online discrete choice study conducted to achieve our objectives; third, we discuss the results and provide managerial recommendations; and fourth, we conclude and provide directions for future research.

\section{Background}

\section{Development of e-Services}

There are three primary reasons for firms to develop eservices. First, Shapiro and Varian (1999) argued that on the margin, consumer acquisition and service costs are generally much lower in an online medium versus that in an offline medium. Lower marginal costs result due to consumers' using the e-service to efficiently search for product information without costly human intervention (Shapiro and Varian 1999) and also due to the ease of eservice scalability (Bitner, Brown, and Meuter 2000).

Second, e-services inexpensively and effectively deliver high-quality, timely, and indepth product information desired by consumers. Lynch and Ariely (1999) found that online consumers for wine significantly valued high quality product information and that with increased quality of product information, consumers became less price sensitive. E-services also provide consumers with benefits such as better price-quality comparisons (Evans and Wurster 1999) and customized search processes based on criteria of importance (Lynch and Ariely 1999).

Finally, the use of e-services enables firms to develop a deep understanding of consumer behavior. The search, evaluation, and purchasing activities conducted using an eservice leave a behavior trail that is recorded, can be analyzed, and then cost-effectively matched to the most appropriate offering available.

\section{Risks Associated with e-Service Offerings}

Creating new capabilities carries the associated risks of making existing capabilities obsolete (Christensen 1997). In creating new e-services, firms might have to write off existing service delivery systems that provide traditional (or non-Web) features. Examples of traditional features include access to expert salespeople who have specialized knowledge that is difficult to obtain elsewhere, customized account management by professionals, and access to brickand-mortar facilities during the entire service delivery cycle. Justifiably, high prices are needed to sustain these high-cost traditional features. Developing e-services might render these traditional capabilities as obsolete and hence are considered as risky by firms.

Furthermore, in creating e-services, firms face the risk that consumers might not immediately prefer the value proposition enabled by the new capability (examples of such eservices include online groceries, retail pharmacies, online banking, and online automobile stores) (Christensen 2001). Consumers shop in an offline environment by visiting stores, talking to salespeople, looking for the best "deals," touching and feeling the product, sampling before 
purchase, searching for information through word-of-mouth recommendations, being influenced at the point of purchase, all the while interacting with a firm's human representatives. Although e-services offer an excellent mode of communicating nonsensory attributes (like nutritional information), they are a poor medium for communicating sensory attributes like touch, smell, taste, and so on (Degeratu, Rangaswamy, and Wu 2000). This situation is problematic for firms that offer traditional sensory features as an integral component of their offerings. Consumers have gotten used to dealing with humans in an offline environment and are loath to give that up for uncertain e-service benefits. Consumers are unlikely to change predictably, and thus firms have to learn about new consumer preferences before developing e-services.

Finally, many firms feel that online commerce involves price battles and lower margins (Lynch and Ariely 1999). They are also concerned that online consumers who have access to more in-depth product information will primarily shop on the basis of price (Sinha 2000). Increased consumer price sensitivity and a price-based competitive landscape make firms hesitate in developing e-services.

However, if current and projected trends are any indication, most firms have no choice but to offer e-services. Therefore, firms need information about consumer preferences, specifically information about how consumers make trade-offs between traditional features, online benefits of real-time access to high-quality and in-depth product information, and price sensitivities. Armed with such information, firms will be able to design e-services that not only match consumer preferences but also effectively combine existing capabilities with new ones to achieve continued profitability.

\section{Consumer Choice of e-Service}

To explain consumer choice of an e-service, we need to consider the relative importance weights that consumers attach to the features that are available to them at the time of purchase (Anderson 1971; Bettman, Capon, and Lutz 1975). When faced with a choice task, consumers are likely to use both features that they are already familiar with and new features that are made available to them (Lynch, Marmorstein, andWeigold 1988). The propensity to use either one or both sets of features is a function of the search costs and benefits associated with processing the information associated with the features (Ratchford 1982). When faced with high search costs and uncertain benefits for some features, consumers are more likely to assign low importance weights to those features (Huber and McCann 1982). On the other hand, consumers are likely to assign high importance weights to features whose search costs are low and whose benefits are more certain. When choosing new products and services, search costs and benefit uncertainty can be reduced by either leveraging prior product feature knowledge to assimilate new feature knowledge (Park, Mothersbaugh, and Feick 1994) or by increasing familiarity with the new features (Alba and Hutchinson 1987). Therefore, to understand consumer choice in e-services, we need to assess how consumers trade off between prior feature knowledge acquired through purchasing offline (i.e., price and other traditional [offline] 
features) and new product feature knowledge (i.e., online-only features). Similarly, we need to understand how consumers trade off between traditional features and online-only features as a function of increasing e-service familiarity. We use discrete choice analysis to achieve the above objectives.

\section{Research Method}

\section{Context}

To achieve our objectives, we needed a research context that satisfied the following criteria. First, because we were interested in comparing offline and online consumers, our research context must allow for purchasing in both offline and online situations. Second, we needed a context wherein existing brick-and-mortar firms face uncertainty as to how exactly to offer e-services. Third, we needed a context in which per transaction prices exist when purchasing via e-services. Finally, practical considerations required that our context allow for data collection using real consumers and appropriate sampling procedures. Therefore, we chose to collect data from a widely used transaction-fee based e-services industry. Confidentiality agreements with the sponsoring organization prohibit us from disclosing the exact industry from which data were collected. However, we can disclose that the e-service industry studied is widely used and is similar to real-estate brokerages, travel agent services, discount brokerage services, auction services, and grocery delivery services. Consumers paid a fee per transaction for the e-service and had access to a vast assortment of products. In this industry, the consumers could also access and purchase a similar assortment of products from a traditional (offline) service provider.

\section{Analysis Approach}

An effective method for determining the relative value of various attributes of a new service involves modeling consumer preferences in response to experimentally designed service profiles. This approach, commonly known as probabilistic discrete choice analysis (DCA) has been used to model choice processes of decision makers in a variety of academic disciplines, including marketing, operations management, transportation, urban planning, hospitality, and natural resource economics (e.g., Louviere and Timmermans 1990; Moore and Pullman 1999; Verma, Thompson, and Louviere, 1999; Verma, Thompson, Moore, and Louviere 2001).

Statistical models (e.g., multinomial logit models) developed from a DCA study link service attributes to consumer preferences. By describing a service in terms of appropriate attributes, DCA can be used to predict market share and profit for any service offering in a competitive environment (Danaher 1997). Recent articles by Verma, Thompson, and Louviere (1999) and Verma, Plaschka, and Louviere (2002) review DCA literature and provide guidelines for designing and conducting DCA studies for services. Rather than repeating what has already been detailed in various publications, here we only briefly describe the DCA method. 
Discrete choice experiments involve careful design of service profiles (a specific service) and choice sets (a number of services) in which two or more service alternatives are offered to decision makers and they are asked to evaluate the options and choose one (or none). Each participant in a DCA experiment typically receives several choice sets to evaluate (e.g., 8 to 32 sets), with two or more hypothetical services to choose from in each set. The design of the experiment is under the control of the researcher, and consequently, the decision makers' choices (dependent variable) are a function of the attributes of each alternative, personal characteristics of the respondents, and unobserved effects captured by the random component (e.g., unobserved heterogeneity or omitted factors). For a detailed theoretical and statistical background of DCA, please refer to Ben-Akiva and Lerman (1991) and McFadden (1986).

DCA applications based on choice experiments typically involve the following steps: (a) identification of attributes, (b) specification of attribute levels, (c) experimental design, (d) presentation of alternatives to respondents, and (e) estimation of the choice model. Past studies have shown that in general, the market share predictions generated from the statistical models (e.g., multinomial logit or MNL)based on DCA are extremely accurate (Ben-Akiva and Lerman 1991; Green and Krieger 1996; Louviève and Timmermans 1990). Although design of choice experiments and estimation of MNL models requires sophisticated training and skills, implementing the estimated model(s) in spreadsheet-based decision support systems is fairly easy. Hence, DCA is very useful for practicing managers and is used here to explore the consumer preferences for e-services.

\section{e-Service Attributes}

Given our conceptual variables of interest, namely, traditional features, online-only features, price per transaction, access to brick-and-mortar facilities, access to the online service via the online medium, and marketing promotions, we chose our attributes on the basis of their judged fit with our conceptual variables. Specifically, we collected qualitative data from four high-level executives in our chosen industry and requested them to suggest online service attributes and levels that reflected our conceptual variables. On the basis of the executives' suggestions and a review of existing online and offline services in our chosen industry, we modified attributes and levels to reflect the dominant market choice drivers. We then showed the new list of attributes to two different executives and also to the initial four executives, and on the basis of their classification, we refined our list of attributes and levels. Finally, we showed our list of attributes to two business school professors, both of whom were blind to the purpose of the study, and asked them to verify our classification. The interrater reliability was very close to $100 \%$, and subsequent discussions resolved any differences.

Table 1 lists our selected attributes, their levels, and their classification into our conceptual variables of interest. In all, we manipulated 11 e-service attributes at two levels each. Our dependent variable was the choice of the e-service. The independent variables (attributes) can be classified in the following broad categories: traditional features, online-only features, price/transaction, marketing promotions, and access to brick-and-mortar backup. 
Traditional features were operationalized by including three attributes: (a) availability of indepth and proprietary research and analysis about the entire product assortment, (b) option of an account managed by a professional for an additional fee, and (c) access to unique new products earlier than the open market. Online-only features were operationalized by including three attributes: (a) availability of real-time product information available anytime and anywhere, (b) access to real-time customized account status, and (c) access to online analytic tools for making better product decisions. Price level was manipulated by varying price per transaction at four levels. In reality, we created two price variables (PRICE1 and PRICE2), within each of which we varied price per transaction at two levels. Access to brick-and-mortar backup was manipulated by including an attribute that allowed accessibility to local branch sales offices. Marketing promotions were manipulated by two attributes: (a) ability to register online and transact immediately, and (b) a special offer for new consumers varied at two levels: 25 free transactions in a given time period or $\$ 100$ credit to open an account. Each of the above attributes, except price sensitivity and special offer, was varied in a binary format, that is, either as being available or not.

\section{Experimental Design}

We created 16 orthogonal fractional factorial profiles that allowed us to reliably estimate all the main effects of the attributes included (Verma, Thompson, and Louviere 1999). To enhance the realism of the task, a full-profile approach was used in presenting the choice sets (Green and Srinivasan 1990), that is, each profile shown to the respondents simultaneously described some combination of all the attributes. To generate the discrete choice sets, we used a "foldover" design (Louviere 1988). A foldover design contains the opposite levels of every attribute for a given profile and therefore presents two completely orthogonal profiles to respondents in each choice set.

We pretested the choice task with 50 randomly selected consumers to ensure ease and comprehension of the task, as well as to ensure reliable data collection methods. Average task completion time was 10 minutes, and respondents did not indicate difficulty in comprehension.

Besides the e-service choice task, the survey instrument included some demographic questions (age, gender, education, marital status). We also asked the respondents to describe the number of times they purchased the specific service during the preceding year. Purchase frequency can be used as a measure of product familiarity (Alba and Hutchinson 1987). In addition, we asked the consumers to rate their individual involvement in the purchasing decision on a 6-point scale. The purpose of including this question was to only select the respondents with a high degree of involvement with the e-service. Only those respondents who indicated a high degree of involvement with the purchase decision (i.e., answered 4 or higher on a 6-point scale) were included in our analysis. By including only involved consumers in our study, we simulated a reasonable decision made by firms to initially target involved and motivated consumers when introducing a new e-service. The next section describes the sampling frame work and the data collection method. 


\begin{tabular}{|c|c|c|}
\hline Construct & Attribute & Level \\
\hline Price $^{a}$ & $\begin{array}{l}\text { Price/transaction in \$ amounts } \\
\text { (PRICE) }\end{array}$ & $\begin{array}{l}\text { Low } \\
\text { Medium } \\
\text { Medium-high } \\
\text { High }\end{array}$ \\
\hline \multirow[t]{3}{*}{$\begin{array}{l}\text { Traditional } \\
\text { services }\end{array}$} & $\begin{array}{l}\text { Availability of in-depth research and } \\
\text { analysis at no additional cost (R\&A) }\end{array}$ & $\begin{array}{l}\text { No } \\
\text { Yes }\end{array}$ \\
\hline & $\begin{array}{l}\text { Option of account management by a } \\
\text { professional staff for additional fee } \\
\text { (PROFMGT) }\end{array}$ & $\begin{array}{l}\text { No } \\
\text { Yes }\end{array}$ \\
\hline & $\begin{array}{l}\text { Access to unique new products earlier } \\
\text { than the open market (NEWPROD) }\end{array}$ & $\begin{array}{l}\text { No } \\
\text { Yes }\end{array}$ \\
\hline \multirow[t]{3}{*}{$\begin{array}{l}\text { Online-only } \\
\text { services }\end{array}$} & $\begin{array}{l}\text { Availability of real-time product } \\
\text { information anytime, anywhere } \\
\text { (REALTIME INFO) }\end{array}$ & $\begin{array}{l}\text { No } \\
\text { Yes }\end{array}$ \\
\hline & $\begin{array}{l}\text { Availability of real-time customized } \\
\text { account status (REALTIME STATUS) }\end{array}$ & $\begin{array}{l}\text { No } \\
\text { Yes }\end{array}$ \\
\hline & $\begin{array}{l}\text { Access to advanced analysis tools for } \\
\text { better decision making (DSSTOOLS) }\end{array}$ & $\begin{array}{l}\text { No } \\
\text { Yes }\end{array}$ \\
\hline $\begin{array}{l}\text { Brick-and- } \\
\text { mortar } \\
\text { backup }\end{array}$ & Access to local branches (BRANCH) & $\begin{array}{l}\text { No } \\
\text { Yes }\end{array}$ \\
\hline \multirow[t]{2}{*}{$\begin{array}{l}\text { New } \\
\text { customer } \\
\text { acquisition }\end{array}$} & $\begin{array}{l}\text { Ability to apply and start using the } \\
\text { account online within minutes } \\
\text { (APPLY ONLINE) }\end{array}$ & $\begin{array}{l}\text { No } \\
\text { Yes }\end{array}$ \\
\hline & $\begin{array}{l}\text { Special offer for new customers } \\
\text { (PROMOTION) }\end{array}$ & $\begin{array}{l}25 \text { free } \\
\text { transactions } \\
\$ 100 \text { Credit }\end{array}$ \\
\hline
\end{tabular}

a. Price per transaction was operationalized as two independent variables (PRICE1 and PRICE2), at two levels each, corresponding to the four pertransaction prices.

Table 1 List of Constructs, Attributes, and Levels

\section{Sample and Data Collection}

The respondents were active consumers in our chosen e-service industry and were part of a demographically balanced panel purchased from a large U.S.-based, nationally reputed marketing research firm. Consumer panels are an appropriate sampling frame and have a rich history of business applications (e.g., Lohse, Bellman, and Johnson 2000). Also, given the lack of choice of sampling frames in studying online behavior, our decision to use a purchased consumer panel is consistent with the current state of the art in the field (Degeratu, Rangaswamy, and Wu 2000).

The purchased panel had 10,000 consumers, and the study was administered to all of them. In other words, we did not randomly sample from our chosen sampling frame but made the experiment available to all the panel consumers. Of the 10,000 consumers, only a negligible percentage (less than $2 \%$ ) chose not to respond. Thus, gross nonresponse bias is not a factor in our study. As discussed earlier, we screened respondents on the basis of their response to a purchase involvement question. After screening for involvement, our sample size was 1,430, 


\begin{tabular}{lccc}
\hline Characteristic & $\begin{array}{c}\text { Total } \\
\text { Sample } \\
(\mathrm{N}=1,430)\end{array}$ & $\begin{array}{c}\text { Online } \\
\text { Segment } \\
(\mathrm{n}=1,150)\end{array}$ & $\begin{array}{c}\text { Offline } \\
\text { Segment } \\
(\mathrm{n}=280)\end{array}$ \\
\hline Age & & & \\
$\quad$ 18 to 34 years & 29 & 30.17 & 23.94 \\
35 to 54 years & 53.9 & 55.40 & 47.85 \\
55+ years & 17.1 & 14.43 & 28.21 \\
Gender & & & \\
$\quad$ Male & 66 & 68.69 & 55 \\
Female & 34 & 31.31 & 45 \\
Marital status & & & \\
$\quad$ Single & 26.6 & 27.73 & 21.78 \\
$\quad$ Married & 57.8 & 57.19 & 58.94 \\
$\quad$ Other & 15.6 & 15.08 & 19.28 \\
Education & & & \\
$\quad$ College + & 82.5 & 83.65 & 77.85 \\
Some college & 15 & 13.85 & 20.35 \\
No college & 2.5 & 2.5 & 1.80 \\
\hline
\end{tabular}

Table 2 Sample Characteristics (in percentages)

leading to a qualified response rate of $14.3 \%$. After data collection, these respondents were divided into groups of offline $(n=280)$ and online consumers $(n=1,150)$ based on self-reported actual offline or online service purchase. Note: The offline segment included consumers who purchase this specific type of service only by the traditional (or offline) medium. The online segment was further subdivided into three groups based on their familiarity and/or usage (low, medium, high) of this specific type of service. Using self-reported frequency of transactions in the past year, four industry experts classified the online segment respondents as low-, moderate-, or high-familiarity consumers. The executives' segmentation recommendations were based on standard industry practices across a wide range of firms in the industry. The sample sizes for each of the three online segments thus created were 782 for low-familiarity online consumers, 221 for moderate-familiarity online consumers, and 147 for high-familiarity online consumers. The final sample thus included segments that purchased either offline or online, with the online segment consisting of three consumer segments with different degrees of online service familiarity.

Sample details and sizes of online and offline segments are presented in Table 2 . As the sample statistics indicate, compared with offline consumers, online consumers are better educated, younger, and are more likely to be men than women. These statistics are in conformance with published studies on online behavior that demonstrate similar sample statistics (Degeratu, Rangswamy, and Wu 2000; Emmanouilides and Hammond 2000). Furthermore, it has been demonstrated that demographics do not significantly affect Internet usage behavior, and hence the demographic differences between offline and online consumers should not influence the choice of an online service (Emmanouilides and Hammond 2000). 
During the data collection phase, each respondent received an e-mail from the research team with an invitation to join the research project. In addition to reimbursement from the marketing research firm for panel participation, each respondent's name was entered in a raffle for winning attractive prizes. After logging into a secure Web site, each respondent then read a common core concept of the online service that held constant various nonexperimental features across all choice sets. The features that were held constant included Web site reliability, on-site support, privacy, security, breadth of product assortment, information quality, and Web site usability. After reading the core concept, each respondent was asked to respond to 16 experimentally generated e-service choice sets. Each choice set contained two versions of the e-service (Table 3). The respondents were asked to choose one of the two presented e-service concepts or indicate that they refused to choose either. Half the respondents made choices in one order that was then reversed for the other half of the respondents. The order made no statistical difference to the results and will not be discussed further. Similar to the pretest, average task completion time was approximately 10 minutes.

\begin{tabular}{|c|c|c|}
\hline Attribute & e-Service 1 & e-Service 2 \\
\hline $\begin{array}{l}\text { Price/transaction (presented in } \\
\text { actual \$ amount to respondents) }\end{array}$ & High & Medium \\
\hline $\begin{array}{l}\text { Availability of in-depth } \\
\text { research and analysis } \\
\text { at no additional cost }\end{array}$ & No & Yes \\
\hline $\begin{array}{l}\text { Option of account management } \\
\text { by a professional staff for }\end{array}$ & & \\
\hline $\begin{array}{l}\text { additional fee } \\
\text { Access to unique new products }\end{array}$ & Yes & No \\
\hline earlier than the open market & Yes & No \\
\hline $\begin{array}{l}\text { Availability of real-time product } \\
\text { information anytime, anywhere }\end{array}$ & No & Yes \\
\hline $\begin{array}{l}\text { Availability of real-time } \\
\text { customized account status }\end{array}$ & No & Yes \\
\hline $\begin{array}{l}\text { Access to advanced analysis tools } \\
\text { for better decision making }\end{array}$ & No & Yes \\
\hline Access to local branches & Yes & No \\
\hline $\begin{array}{l}\text { Ability to apply and start using the } \\
\text { account online within minutes }\end{array}$ & No & Yes \\
\hline Special offer for new customers & $\begin{array}{l}\$ 100 \\
\text { credit }\end{array}$ & $\begin{array}{l}25 \text { free } \\
\text { transactions }\end{array}$ \\
\hline I choose to use this e-service $\rightarrow$ & & \\
\hline
\end{tabular}

Table 3 A sample e-Service Choice Set

\section{Analysis and Results}

The choice data were analyzed using the maximum likelihood estimation and by developing MNL models for the five segments, namely, offline, online, low familiarity online, 
medium familiarity online, high familiarity online (Louviere and Woodworth 1983; Verma, Thompson, and Louviere 1999).

\section{Statistical Comparison of Estimated MNL Models}

A direct comparison of utilities or beta parameters for two MNL models is inappropriate because the models contain an embedded Gumbel scale parameter, which may not be same for the two models being compared. Therefore, we used an appropriate chi-square test developed by Swait and Louviere (1993) to test the similarities or differences across estimated MNL models. This procedure first identifies the optimal Gumbel scale for the second model relative to the first and then compares the two models using a chi-square statistic. Table 4 presents summarized statistical information about the Swait-Louviere chi-square rescaling test conducted for various e-service segments. As Table 4 indicates, all the estimated models are significantly different from each other. Swait and Louviere (1993) further recommended that the estimated beta parameters for two MNL models can be plotted against each other to test if

\begin{tabular}{lcccc}
\hline $\begin{array}{l}\text { First MNL model } \\
\text { Second MNL model }\end{array}$ & $\begin{array}{c}\text { Offline } \\
\text { All online }\end{array}$ & $\begin{array}{c}\text { Offline } \\
\text { Low } \\
\text { online }\end{array}$ & $\begin{array}{c}\text { Offline } \\
\text { Medium } \\
\text { online }\end{array}$ & $\begin{array}{l}\text { Offline } \\
\text { High } \\
\text { online }\end{array}$ \\
\hline $\begin{array}{l}\text { LL }(\beta) \text { for Model 1 } \\
\quad \text { or } L L_{1}\end{array}$ & -95.18 & -95.18 & -95.18 & -95.18 \\
LL ( $\beta$ ) for Model 2 & & & & \\
$\quad$ or $L L_{2}$ & -157.35 & -116.27 & -156.80 & -89.47 \\
Optimum $\mu$ & 1.1133 & 0.9908 & 1.2227 & 0.8288 \\
LL $(\beta)$ for combined & & & & \\
model after rescaling \\
or $L L \mu$
\end{tabular}

Table 4 Swait-Louviere Chi-Square Test for Comparing Multinomial Logit (MNL) Models for Various Segments

the two models are proportional to each other (i.e., to test whether the only difference between the two models is the Gumbel scale parameter). If the scatter plot of two sets of beta parameters is not a straight line, then it further proves that the two models are different from each other. Figure 1 presents a scatter plot of beta parameters that are not aligned along a straight line, demonstrating that the estimated MNL models are indeed different from each other.

We found overall that the five models (offline, online, low familiarity online, medium familiarity online, high familiarity online) are significantly different from each other $(p<.05)$, thereby indicating that the choice behavior of offline consumers is different from online 
consumers classified into low-, medium-, or high-familiarity segments. The attribute partworths (beta parameters) for the five estimated choice models are included in Table 5.
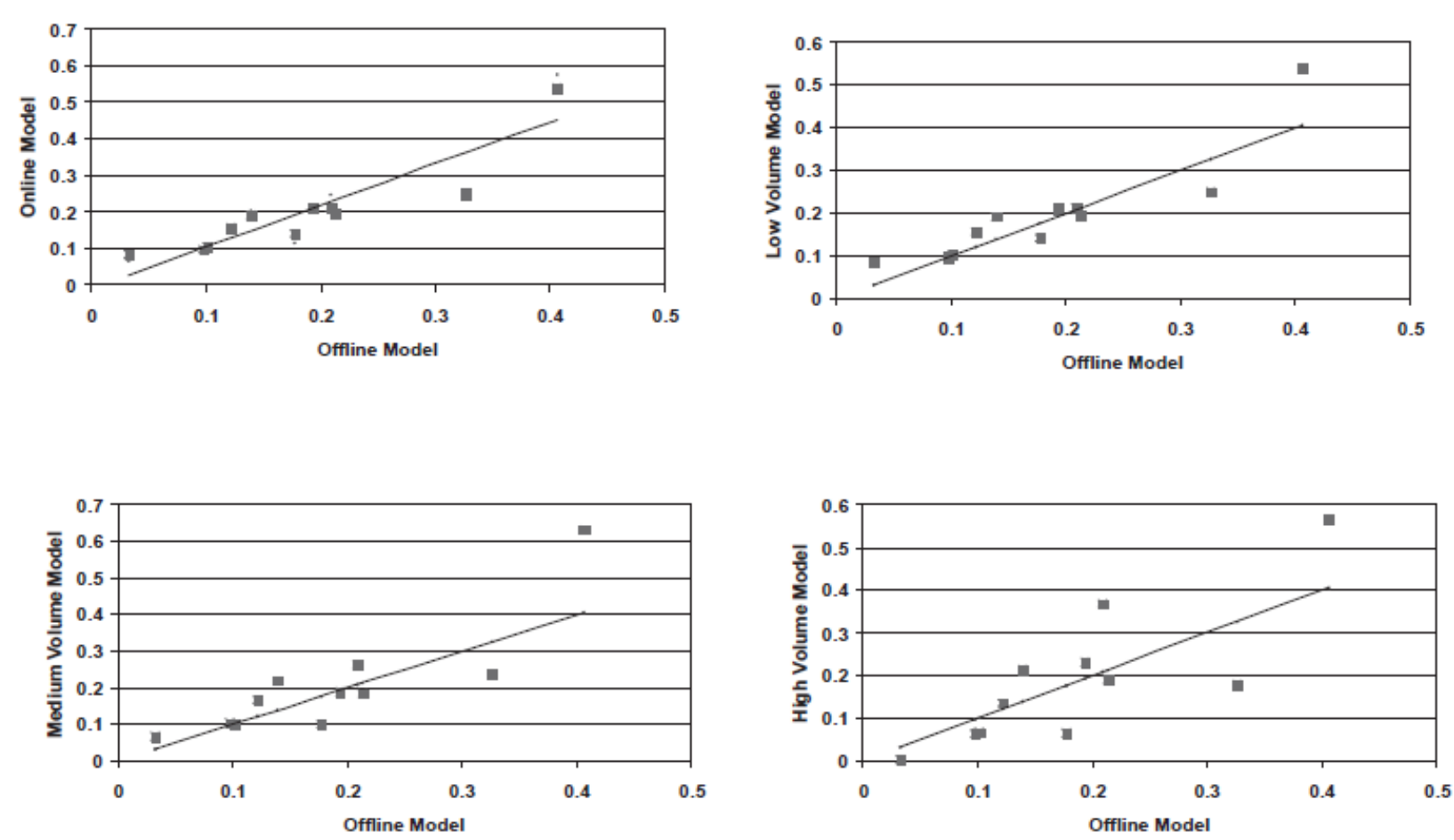

Figure 1 Part-Worth Utilities Plotted in Pairs as Suggested by Swait and Louviere (1993)

\section{Trade-Offs Between Traditional (non-Web) and Online-Only Features}

The first objective of our study deals with the trade-offs that consumers make between traditional (non-Web) features and online-only features. We state results highlighting the trade-offs for offline consumers and online consumers. We then also state results comparing offline and online consumers.

Offline consumers. As discussed earlier, consumer theory states that consumers weight prior feature knowledge higher than new feature knowledge. Our results broadly support consumer choice theory. Generally, offline consumers attach higher weights to traditional (nonWeb) features than to online-only features. Offline consumers value the availability of research and analysis (R\&A) higher than all the online-only features of an e-service, namely, availability of real-time information (REALTIME INFO), availability of real-time status (REALTIME STATUS), and availability of online decision-support tools (DSSTOOLS) (R\&A = 0.3262, REALTIME INFO = 0.2089, REALTIME STATUS $=0.2127$, DSTOOLS $=0.0971, p<.05)$.

Offline consumers also value availability of professionally managed accounts (PROFMGT) more than availability of online decision-support tools (DSSTOOLS) (PROFMGT = 
0.177 , DSSTOOLS $=0.0971, p<.05)$. However, access to new products earlier than the open market (NEWPROD) was not weighted differently than any online feature of the e-service.

Within traditional features, availability of $R \& A$ was valued more than availability of professionally managed accounts ( $R \& A=0.3262$, PROFMGT $=0.177, p<.05)$. Within online-only features, availability of real-time information (REALTIME INFO) and availability of real-time status (REALTIME STATUS) were valued equally, and both these online-only features were valued more than availability of online decision-support tools (DSSTOOLS) (REALTIME INFO = 0.2089, REALTIME STATUS $=0.2127$, DSTOOLS $=0.0971, p<.05)$. Thus, the results for offline consumers broadly confirm theoretical predictions.

Online consumers. Online consumers, according to theory, should attach higher weights to online-only features than to traditional (non-Web) features. Our results provide partial support for the predictions. Among online only features, availability of real-time information (REALTIME INFO) is valued more than availability of professionally managed accounts (PROFMGT) and access to new products earlier than the open market (NEWPROD) (REALTIME INFO $=0.2582$, PROFMGT $=0.1158$, NEWPROD $=0.2038, p<.05$ ). Availability of real-time status (REALTIME STATUS) was valued higher than availability of professionally managed accounts (PROFMGT) (REALTIME STATUS = 0.1903, PROFMGT = 0.1158, $p<.05$ ).

Interestingly, availability of R\&A, a traditional feature, was valued equally as one onlineonly feature, that is, availability of real-time information (REALTIME INFO), and actually valued more than two other online-only features, that is, availability of real-time status (REALTIME STATUS) and availability of decision-support tools (DSSTOOLS) (R\&A $=0.2361$, REALTIME STATUS $=0.1903$, DSSTOOLS $=0.0954, p<.05)$.

Within online-only features, all three features were valued differently from each other, with availability of real-time information (REALTIME INFO) being valued the highest, next being availability of real-time status (REALTIME STATUS), and the least valued online feature was availability of decision-support tools (DSSTOOLS) (REALTIME INFO $=0.2582$, REALTIME STATUS $=0.1903$, DSSTOOLS $=0.0954, p<.05)$. Within traditional features, availability of R\&A and access to new products earlier than the open market (NEWPROD) were valued equally, and both these traditional features were valued more than availability of professionally managed accounts (PROFMGT) (R\&A =0.2361, NEWPROD $=0.2038$, PROFMGT $=0.1158, p<.05)$. Thus, with some exceptions, the results for the online segment also support theoretical predictions.

Comparing offline and online consumers. In keeping with the logic developed earlier, we should expect offline consumers to value traditional (non-Web) features more than online consumers and conversely value online-only features less than online consumers. The results provide some support for our theoretical contentions.

Online consumers attach lower importance weights to traditional features than offline consumers. Specifically, online consumers value availability of research and analysis (R\&A) (online $=0.2361$, offline $=0.3262, p<0.05$ ), and professional management (PROFMGT) (online 
$=0.1158$, offline $=0.1770, p<.05)$ less than offline consumers. However, the importance of access to new products earlier than the open market (NEWPROD) was approximately same for both segments.

Interestingly, none of the three online-only features, associated with the e-service, was found to be of higher importance for the online segment as compared with the offline segment. Thus, there was no significant difference in the weights assigned by both online and offline consumers to availability of real-time information (REALTIME INFO), availability of real-time status (REALTIME STATUS), and availability of decision-support tools (DSSTOOLS).

\begin{tabular}{|c|c|c|c|c|c|c|}
\hline Construct & Attribute & $\begin{array}{l}\text { Offline } \\
\text { Segment }\end{array}$ & $\begin{array}{l}\text { All Online } \\
\text { Customers }\end{array}$ & $\begin{array}{c}\text { Low- } \\
\text { Familiarity } \\
\text { Segment }\end{array}$ & $\begin{array}{c}\text { Medium- } \\
\text { Familiarity } \\
\text { Segment }\end{array}$ & $\begin{array}{c}\text { High- } \\
\text { Familiarity } \\
\text { Segment }\end{array}$ \\
\hline \multirow[t]{2}{*}{ Price } & PRICE 1 & $\begin{array}{r}-0.4058 \\
(0.0236)\end{array}$ & $\begin{array}{l}-0.5769 \\
(0.0108)\end{array}$ & $\begin{array}{l}-0.5398 \\
(0.0151)\end{array}$ & $\begin{array}{l}-0.6327 \\
(0.0263)\end{array}$ & $\begin{array}{r}-0.5670 \\
(0.0317)\end{array}$ \\
\hline & PRICE 2 & $\begin{array}{l}-0.1388 \\
(0.0228)\end{array}$ & $\begin{array}{c}-0.2034 \\
(0.0119)\end{array}$ & $\begin{array}{l}-0.1911 \\
(0.0144)\end{array}$ & $\begin{array}{l}-0.2188 \\
(0.0178)\end{array}$ & $\begin{array}{c}-0.2149 \\
(0.0316)\end{array}$ \\
\hline \multirow[t]{3}{*}{ Traditional services } & R\&A & $\begin{array}{c}0.3262 \\
(0.0233)\end{array}$ & $\begin{array}{c}0.2361 \\
(0.0102)\end{array}$ & $\begin{array}{c}0.2498 \\
(0.0144)\end{array}$ & $\begin{array}{c}0.2385 \\
(0.0166)\end{array}$ & $\begin{array}{l}0.1788 \\
(0.0299)\end{array}$ \\
\hline & PROFMGT & $\begin{array}{c}0.1770 \\
(0.0229)\end{array}$ & $\begin{array}{l}0.1158 \\
(0.0101)\end{array}$ & $\begin{array}{c}0.1420 \\
(0.0143)\end{array}$ & $\begin{array}{c}0.1006 \\
(0.0164)\end{array}$ & $\begin{array}{c}0.0645 \\
(0.0294)\end{array}$ \\
\hline & NEWPROD & $\begin{array}{c}0.1929 \\
(0.2296)\end{array}$ & $\begin{array}{c}0.2038 \\
(0.0102)\end{array}$ & $\begin{array}{c}0.2107 \\
(0.0144)\end{array}$ & $\begin{array}{c}0.1899 \\
(0.0166)\end{array}$ & $\begin{array}{c}0.2319 \\
(0.0302)\end{array}$ \\
\hline \multirow[t]{3}{*}{ Online-only services } & REALTIME INFO & $\begin{array}{c}0.2089 \\
(0.0239)\end{array}$ & $\begin{array}{c}0.2482 \\
(0.0102)\end{array}$ & $\begin{array}{c}0.2123 \\
(0.0144)\end{array}$ & $\begin{array}{c}0.2624 \\
(0.0168)\end{array}$ & $\begin{array}{c}0.3680 \\
(0.0308)\end{array}$ \\
\hline & REALTIME STATUS & $\begin{array}{c}0.2127 \\
(0.0230)\end{array}$ & $\begin{array}{c}0.1903 \\
(0.0117)\end{array}$ & $\begin{array}{c}0.1949 \\
(0.0143)\end{array}$ & $\begin{array}{c}0.1858 \\
(0.0166)\end{array}$ & $\begin{array}{c}0.1897 \\
(0.0299)\end{array}$ \\
\hline & DSSTOOLS & $\begin{array}{c}0.0971 \\
(0.0227)\end{array}$ & $\begin{array}{c}0.0954 \\
(0.0099)\end{array}$ & $\begin{array}{c}0.0978 \\
(0.0141)\end{array}$ & $\begin{array}{c}0.1044 \\
(0.0161)\end{array}$ & $\begin{array}{c}0.0628 \\
(0.0287)\end{array}$ \\
\hline Brick-and-mortar backup & BRANCH & $\begin{array}{c}0.1006 \\
(0.0227)\end{array}$ & $\begin{array}{c}0.0971 \\
(0.0010)\end{array}$ & $\begin{array}{c}0.1036 \\
(0.0141)\end{array}$ & $\begin{array}{c}0.1214 \\
(0.0163)\end{array}$ & $\begin{array}{c}0.0674 \\
(0.0293)\end{array}$ \\
\hline \multirow[t]{4}{*}{ New customer acquisition } & APPLY ONLINE & $\begin{array}{c}0.1209 \\
(0.0227)\end{array}$ & $\begin{array}{c}0.1581 \\
(0.0100)\end{array}$ & $\begin{array}{c}0.1563 \\
(0.0142)\end{array}$ & $\begin{array}{c}0.2046 \\
(0.0164)\end{array}$ & $\begin{array}{c}0.1369 \\
(0.0292)\end{array}$ \\
\hline & PROMOTION $^{\mathrm{a}}$ & 0.0319 & 0.0675 & 0.0851 & 0.0817 & 0.0034 \\
\hline & INTERCEPT & $\begin{array}{c}(0.0227) \\
-0.7851 \\
(0.0322)\end{array}$ & $\begin{array}{c}(0.0100) \\
-0.3770 \\
(0.0155)\end{array}$ & $\begin{array}{c}(0.0141) \\
-0.5471 \\
(0.0211)\end{array}$ & $\begin{array}{c}(0.0164) \\
-0.2012 \\
(0.0263)\end{array}$ & $\begin{array}{c}(0.0293) \\
-0.1565 \\
(0.0475)\end{array}$ \\
\hline & $\begin{array}{l}\text { Aggregate } \rho^{2} \\
\text { Aggregate adjusted } \rho^{2}\end{array}$ & $\begin{array}{l}.8619 \\
.8445\end{array}$ & $\begin{array}{l}.9442 \\
.9399\end{array}$ & $\begin{array}{l}.9211 \\
.9130\end{array}$ & $\begin{array}{l}.8772 \\
.8678\end{array}$ & $\begin{array}{l}.7769 \\
.7469\end{array}$ \\
\hline
\end{tabular}

Numbers in parentheses are standard errors of individual beta coefficients. $P R I C E=$ price/transaction in $\$$ amounts; R\&A = availability of in-depth research and analysis at no additional cost; PROFMGT = option of account management by a professional staff for additional fee; NEWPROD $=$ access to unique new products earlier than the open market; REALTIME INFO = availability of real-time product information anytime, anywhere; REALTIME STATUS $=$ availability of real-time customized account status; DSSTOOLS $=$ access to advanced analysis tools for better decision making; $\mathrm{BRANCH}=$ access to local branches; APPLY ONLINE $=$ ability to apply and start using the account online within minutes; PROMOTION $=$ special offer for new customers.

a. All attributes except promotion are significant at the .001 level.

Table 5 Estimated Multinational Logit Choice Models for Various Customer Segments

\section{Impact of e-Service Familiarity}

Our second objective was to empirically determine whether increasing e-service familiarity would affect the weights assigned by already online consumers to traditional features, online-only features, brick-and-mortar backup, and marketing promotions. 
The results suggest some differences between the utilities for various features for low-, moderate-, and high familiarity online consumers. A priori, given existing consumer theory on the role of product familiarity (Alba and Hutchinson 1987), we expect the weights assigned to traditional features to decrease and the weight assigned to online-only features to increase as e-service familiarity increased. Our results provide some support for the above contention. Of all the traditional features, we find that the weights assigned to availability of R\&A (R\&A low familiarity $=0.2498, R \& A$ medium familiarity $=0.2385, R \& A$ high familiarity $=0.1788, p<.05$ ) and to the availability of professionally managed accounts (PROFMGT) (PROFMGT low familiarity $=0.142$, PROFMGT medium familiarity $=0.1006$, PROFMGT high familiarity $=0.0645$, $p<.05)$ decrease with increasing e-service familiarity. NEWPROD is not significantly different with increasing e-service familiarity.

With respect to all the online-only features, we find that weights assigned to only availability of real-time information significantly increase with increasing e-service familiarity (RTINFO low familiarity $=0.2123$, RTINFO medium familiarity $=0.2624$, RTINFO high familiarity $=$ $0.368, p<.05)$. All the other online-only features are equally valued despite increasing e-service familiarity.

Also, no significant differences were found in the weights assigned to access to brickand-mortar branches and types of marketing promotions as a function of increasing e-service familiarity. To summarize then, there are some statistical differences between estimated choice models for the three online segments providing support for a priori theoretical predictions based on consumer choice theory.

\section{$\underline{\text { Price Sensitivities }}$}

Our third objective dealt with determining empirically the changes in per-transaction price sensitivity as a function of mode of purchase and also as a function of increasing e-service familiarity. Because the results are identical irrespective of per-transaction price level, we only discuss the results with respect to changes between one set of price levels (medium-high to high, i.e., PRICE1).

Price sensitivity is found to significantly affect eservice choice irrespective of segment affiliation. Online consumers are more price sensitive than offline consumers (offline $=-0.4058$, online $=-0.5769, p<.05)$. Among the three online segments, we find that medium-familiarity online consumers attach the highest weights to price sensitivity in comparison with low- and high-familiarity online consumers, between whom there was no statistical difference in weights assigned to price sensitivity (low familiarity $=0.5398$, medium familiarity $=0.6327$, high familiarity $=0.567, p<.05)$.

Figure 2 presents the price sensitivity curves for offline and online segments. It can be clearly seen that online segment is more sensitive to changes in price compared with the offline segment. Also, as stated above, among the three online segments (low, medium, and high), the medium familiarity segment appears to be the most price sensitive. 


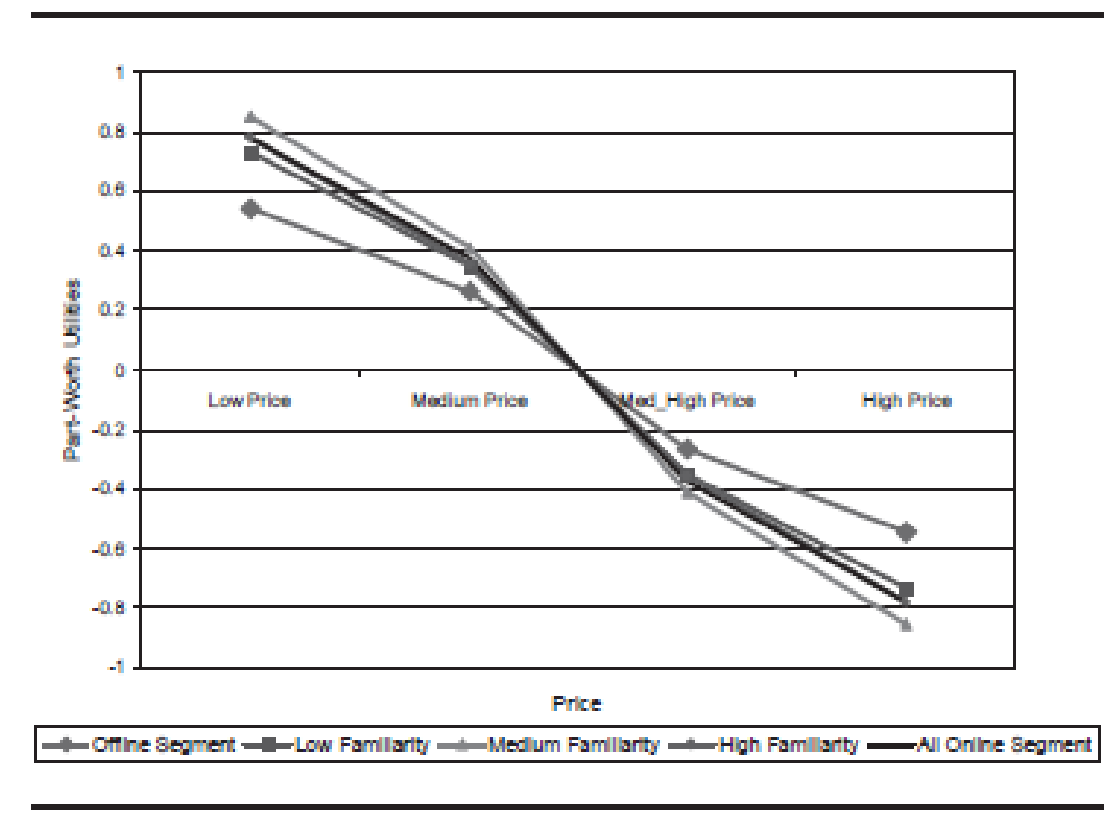

Figure 2 Price Sensitivities

\section{Beyond Statistic - Actionable Results for Managers}

In addition to statistical comparisons of choice models, it is often helpful to analyze the results graphically. Visual representation of attribute utility scores provides managerially useful information that can be used for post hoc analyses and for developing guidelines for implementation. Figure 3 represents the relative utilities for each attribute for all the segments. The sizes of the bar chart represent utilities for each attribute normalized with respect to sum of utilities for each individual model in the exponential format,

$$
\frac{e^{\beta}}{\sum e^{\beta}}
$$

according to the MNL model formulation. Comparing the importance of attributes in the above format allows us to assess the relative impact on the preference share if availability of a certain attribute is changed (e.g., not offered vs. offered). Such a graphic analysis or use of spreadsheet based "what-ifs" are recommended by past studies whenever managerial impact of changes in attribute levels is investigated (e.g., Verma, Plaschka and Louviere, 2002). Figure 3 shows that relative preference share impact potential differs across attributes and across segments. For example, the impact of PROFMGT seems to decrease as online usage frequency and/or familiarity increases. Availability and nonavailability of few attributes seem to make a large impact (e.g., REALTIME INFO for the low-familiarity segment, R\&A for the offline segment). Similar other interesting trends regarding the relative preference share impact of changes in other attributes can be easily observed in Figure 3. Thus, practicing managers can use the results provided in Figure 3 to determine attributes that make the most impact and accordingly allocate resources in an effective manner. 


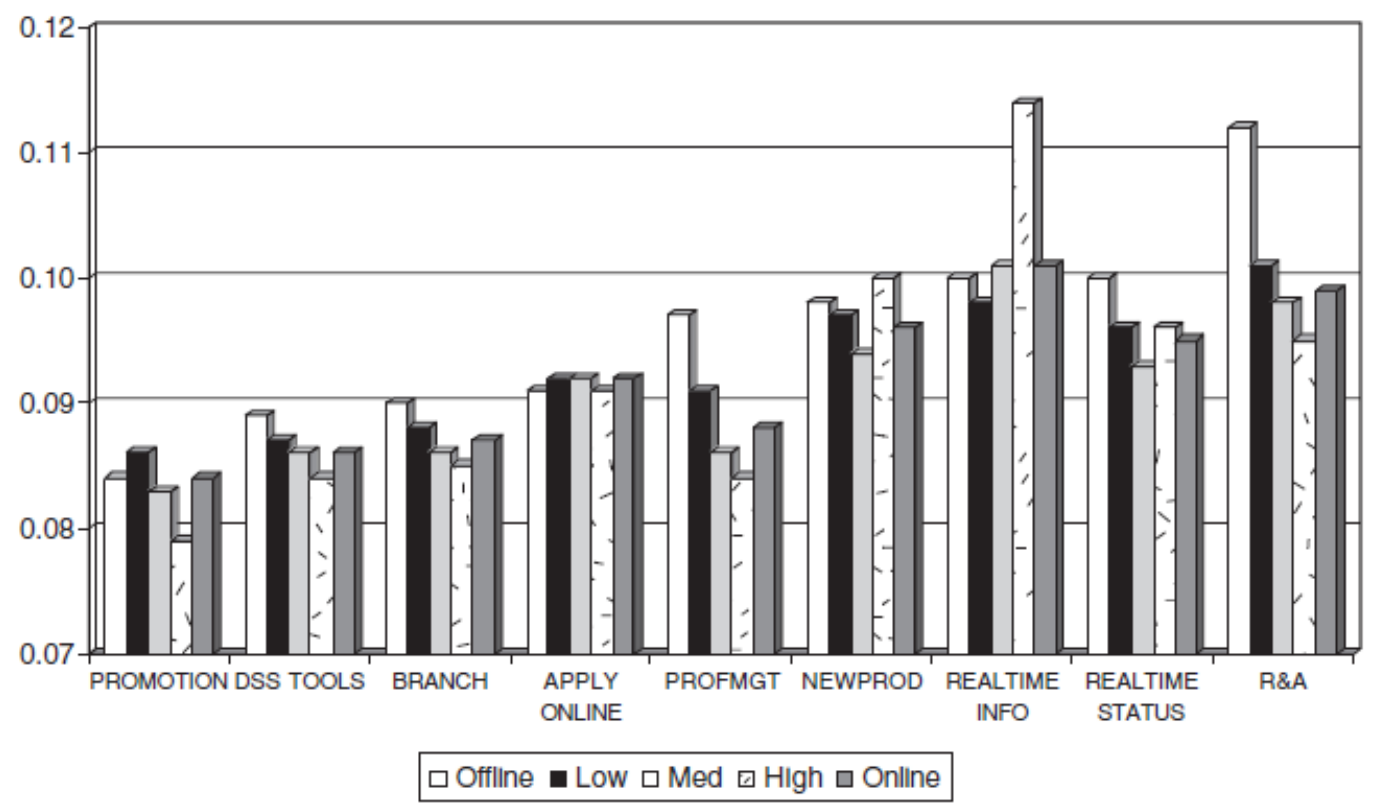

NOTE: REALTIME INFO = availability of real-time product information anytime, anywhere; REALTIME STATUS = availability of real-time customized account status; PROFMGT = option of account management by a professional staff for additional fee; R\&A = availability of in-depth research and analysis at no additional cost; NEWPROD $=$ access to unique new products earlier than the open market; DSSTOOLS $=$ access to advanced analysis tools for better decision making; BRANCH = access to local branches; APPLY ONLINE = ability to apply and start using the account online within minutes; PROMOTION $=$ special offer for new customers.

Figure 3 Relative Preference Share Impact of the Attributes

\section{Discussion and Managerial Implications}

Our study set out to explore the value drivers for various segments in e-services. Broadly speaking, the results suggest that consumers will value e-services providing a combination of traditional and online-only features, at appropriate per-transaction price levels.

However, the results also show that all the consumer segments differ with respect to their relative feature preferences for e-services. Offline consumers value traditional features more than online consumers but find online-only features, access to brick-and-mortar backup, and ability to apply online equally important as online consumers. Furthermore, offline consumers are price sensitive albeit not as much as online consumers. These results might indicate why several pure dot.com firms are failing, whereas a larger number of established brick-and-mortar players are thriving even in the e-services arena. Pure dot.com firms competed on the basis of new online value-added features and price; however, as our results indicate, both offline and online consumers also need traditional features and some access to brick-and-mortar backup-features that brick-and-mortar firms are best equipped to provide. Furthermore, traditional services are part of the core service that all consumers expect, and hence it is not completely surprising that all consumers value traditional services.

Online consumers are definitely more sensitive to price per transaction than are offline consumers. In this sense, creating new e-services represents a double-edged sword for brick- 
and-mortar firms. On one hand, traditional features need to still be provided and new onlineonly features need to be added, but price sensitivity also increases. However, this increase in price sensitivity can perhaps be offset by the lower marginal costs of consumer acquisition/ service. Also, the fact that price sensitivity decreases at a high level of e-service familiarity allows firms to offset the addition of new online-only features by getting consumers to a high degree of e-service familiarity as quickly as possible.

Online consumers also place equal emphasis on availability of research and analysis and on availability of real-time information, suggesting that these consumers not only value timeliness of information but also the quality of information. These results confirm earlier findings that the online medium not only provides timely information but also depth and breadth of information (Lynch and Ariely 1999; Shapiro and Varian 1999). Online consumers value this access to high-quality information even more than other online-only features, further highlighting the power of the online medium in providing rich information.

We also find that the relative weights for various value drivers differ depending on levels of e-service familiarity. Online consumers, in general, need traditional features, onlineonly features, access to brick-and-mortar backup, access via the online medium, and a lower price per transaction. It also appears that moderate-familiarity online consumers attach higher value to a wider range of features than do either low- or high-familiarity online consumers. We can perhaps postulate that moderate-familiarity online consumers seem to have developed a level of comfort with online services inasmuch as that they are able to process and use information on a number of features. These consumers are also the most demanding in that they comfortably straddle both offline and online environments and demand the best of each at a very high level of per-transaction price sensitivity. These results conform to several other studies that find an inverted- $U$ relationship between number of features considered important, that is, amount of information searched and consumer product familiarity (cf. Bettman and Park 1980; Johnson and Russo 1984; Moorthy, Ratchford, and Talukdar 1997). Johnson and Russo (1984) attributed the increasing part of the inverted-U curve to consumers' increasing ability to encode new feature information with increased familiarity and the decreasing part to the increasing ability to ignore irrelevant feature information. Relatedly, Moorthy, Ratchford, and Talukdar (1997) demonstrated that consumers with low product familiarity have difficulty making distinctions between brands, that is, face high search costs, and hence do not engage in a detailed search process. However, as product familiarity increases, consumers are able to make finer distinctions between brands using a wider range of attributes, and hence due to lower search costs, they increase the search process. Finally, as product familiarity increases to a great level, consumers face relatively little uncertainty about brands and their attributes. They are able to make very fine distinctions about the predictive ability of most attributes. At this stage, consumers focus on only the most relevant attributes and intentionally ignore other attributes because search becomes a non-value-adding activity. In other words, our findings, that moderate-familiarity consumers attach the highest importance to all features when compared with low- and high-familiarity consumers, confirm existing consumer choice theory. 
Low- and high-familiarity consumers are less demanding and also seem to value features differently when choosing online services. Low-familiarity consumers are quite similar to offline consumers in that they attach higher importance to features that are more "offline" in nature, namely, traditional features such as availability of research and analysis and availability of professionally managed accounts. High-familiarity online consumers, on the other hand, have the most evolved preferences of all online consumers. High-familiarity online consumers also seem the least demanding. They attach relatively lower value to most online-only features, access via the online medium, and price per transaction than do low-familiarity online consumers. The only feature that high-familiarity consumers value to a greater extent than lowfamiliarity consumers is access to real-time, anytime, anywhere information, confirming existing consumer choice theory. As predicted by existing consumer choice theory, as product familiarity increases, consumers tend to focus on attributes that best predict performance and tend to discount other attributes (Alba and Hutchinson 1987). In our study, most of the eservice attributes included dealt with helping consumers cope with purchasing in the online medium, for example, option of account management by a professional staff for additional fee, availability of real-time customized account status, access to local branches, and ability to apply and start using the account online within minutes. Only two features, namely, availability of indepth research and analysis at no additional cost and availability of real-time product information anytime anywhere dealt with information about the performance of product assortment itself. It is reasonable to assume that high-familiarity online consumers do not need much help coping with purchasing in the online medium and hence discount the attributes that provide this information. However, high-familiarity online consumers, as predicted by theory, will use information that predicts product performance. Because the online medium increases the speed of transacting, it is logical to find that the feature that high-familiarity consumers value the most is availability of real-time information rather than availability of in-depth research and analysis, which is a traditional feature. Finally, high-familiarity online consumers are the least price sensitive, and this is encouraging news for existing brick-and-mortar firms. The price sensitivity results confirm Lynch and Ariely's (1999) findings that as availability of high-quality information increases (in our study, availability of real-time information), price sensitivity decreases.

Once again, it appears brick-and-mortar firms are best positioned to satisfy online consumers by e-service offerings. To the extent that online consumers possess only low and moderate levels of familiarity, existing brick-and-mortar firms can develop appropriate capabilities to satisfy them. These capabilities include those that are needed to provide traditional features and access to brick-and-mortar backup. They also include developing capabilities such as those required to provide online-only features and access via the online medium. To the extent that online consumers develop a high level of familiarity, existing brickand-mortar firms also stand to gain and profit. Satisfying high-familiarity consumers involves consolidating, but not completely eliminating, capabilities that provide traditional services and access to brick-and-mortar backup, as well as maintaining, but not expanding, capabilities that 
provide online value-added features and access via the online medium. Maintaining capabilities rather than expanding them implies a steady cost of operations rather than an increasing one. If we add the possibility of lower marginal costs by serving consumers online, the profit implications become more defined. Furthermore, to add to the above stated advantages of existing brick-and-mortar firms stands the strong finding that high-familiarity consumers are less price sensitive than low- and moderate-familiarity consumers. This implies a certain level of pricing flexibility that only serves to add to the advantages of existing brick-and-mortar firms and also increases the upside potential of not only satisfying consumers online but also of increasing their online transaction frequency, that is, their familiarity.

Our study permits us to infer what features need to be emphasized to effectively design e-services. Table 5 reports the intercepts for each of our estimated models. The intercepts represent the likelihood of choosing an eservice versus an offline service. In other words, the intercepts represent barriers that must be scaled in order to get consumers to choose an online service. If we focus on the offline segment, we can see that the utilities for none of the individual features, including change in price per transaction, are sufficiently high to permit offline consumers to choose an e-service. Given our conceptual variables of interest, we create aggregate utilities for traditional features (R\&A + PROFMGT + NEWPROD; $0.33+0.18+0.19=$ 0.70 ) and online-only features (REALTIME INFO + REALTIME STATUS + DSSTOOLS; $0.21+0.21+$ $0.1=0.52$ ). Note that neither traditional features nor online only features by themselves are sufficient to overcome the barrier (0.78). Interestingly, if we combine traditional features $(0.33$, 0.18 , and 0.19$)$, online-only features $(0.21,0.21$, and 0.1$)$, and change in price per transaction from high to medium-high (0.41), then the created e-service is valued sufficiently by offline consumers to overcome the transition barrier. These findings explain why both pure dot.com firms as well as existing brick-and-mortar forms were able to transition offline consumers into using the online medium. A firm like etrade.com uses a combination of online-only features and change in price per transaction $(0.52+0.41=0.93)$ in designing e-services, whereas a firm such as Charles Schwab uses a combination of traditional features and online-only features $(0.70+$ $0.41=1.21$ ) in its e-service design. In this stylized example, a firm like Charles Schwab need not engage in price competition to transition offline consumers. However, a firm like e-trade must compete by reducing price $(0.52+0.41=0.93)$. Hence, based on the results of our study, Charles Schwab is better positioned to provide a more valued set of features in its e-service offering.

\section{Limitations and Further Research}

Our study, although among the few to study e-service choice behavior, has some limitations. First, it is a single industry study and hence has limited generalizability. Further research needs to be conducted that expands the scope of the findings to industries beyond the one that we studied. Examples of such research exist in the travel industry (Shankar, Rangawamy, and Pusateri 1999), the wine industry (Lynch and Ariely 1999), and the grocery 
industry (Degeratu, Rangaswamy, and Wu 2000). Second, our study used a common operationalization of online service familiarity, that is, number of transactions per year. Future research needs to expand the definition and the operationalization of product familiarity to include more cognitive measures (Alba and Hutchinson 1987). Third, although our results permit us to make generalizations about various consumer segments, our study is essentially a cross-sectional one. We need more research that tracks the same set of consumers as they evolve from low familiarity consumers into high-familiarity ones. This type of longitudinal panel research of online choice behavior is enabled by using the WhartonVirtual Test Panel (see Lohse, Bellman, and Johnson 2000 for details). Fourth, we used industry-defined criteria for segmentation. Future research needs to use latent class and other segmentation techniques to allow segments to emerge from the data, thus accounting for heterogeneity that may exist between segments (cf. Degeratu, Rangaswamy, and Wu 2000). Fifth, our study limited the consumer sample to high involvement consumers. Future research needs to be conducted to see if these results are replicated among low involvement consumers. Finally, our results apply only to current consumers of the service. Over time, current offline consumers may migrate to become online consumers, potentially altering our reported results. However, despite the limitations, we believe that our results and conclusions add to existing scholarship on developing transaction-based e-services and also enable managers to create e-services that best satisfy the consumer segments targeted.

\section{References}

Alba, Joseph W. and J. Wesley Hutchinson (1987), "Dimensions of Consumer Expertise," Journal of Consumer Research, 13, 411-54.

Anderson, Norman H. (1971), "Integration Theory and Attitude Change," Psychological Review, 78, 171-206.

Ben-Akiva, M. and S. R. Lerman (1991), Discrete Choice Analysis. Cambridge, MA: MIT Press.

Bettman, James R., Noel Capon, and Richard J. Lutz (1975), “Cognitive Algebra in Multi Attribute Models," Journal of Marketing Research, 12, 151-64.

and C. Whan Park(1980), "Effects of Prior Knowledge on Experience and Phase of the Choice Process on Consumers' Decision Processes: A Protocol Analysis," Journal of Consumer Research, 7 (December), 234-48.

Bitner, Mary Jo, Stephen W. Brown, and Matthew L. Meuter (2000), "Technology Infusion in Service Encounters," Journal of the Academy of Marketing Science, 28 (Winter), 138-49.

Christensen, Clayton M. (1997), The Innovator's Dilemma: When New Technologies Cause Great Firms to Fail. Boston: Harvard Business School Press.

(2001), After the Gold Rush. Cambridge, MA: Innosight LLC. 
Danaher, P. J. (1997), "Using Conjoint Analysis to Determine the Relative Importance of Service Attributes Measured in Customer Satisfaction Surveys," Journal of Retailing, 73 (2), 23560.

Degeratu, Alexandru, Arvind Rangaswamy, and Jeremy Wu (2000), "Consumer Choice Behavior in Online and Regular Stores: The Effects of Brand Name, Price, and Other Search Attributes," International Journal of Research in Marketing, 17:55-78.

Emmanouilides, Christos and Kathy Hammond (2000), "Internet Usage: Predictors of Active Users and Frequency of Use," Journal of Interactive Marketing, 14 (2), 17-32.

Evans, Philip and Thomas S.Wurster (1999), "Getting Real about Virtual Commerce," Harvard Business Review, 77 (November/December), 84-94.

Green, P. E. and A. M. Krieger (1996), "Individualized Hybrid Models for Conjoint Analysis," Management Science, 42 (6), 850-67.

_ and V. Srinivasan (1990), "Conjoint Analysis in Marketing: New Developments with Implications for Research and Practice," Journal of Marketing, 54 (October), 3-19.

Han, D. and J. Han (2002), "Value-Based Strategy for Internet Business" working paper, Korea University, Seoul, Korea.

Huber, Joel and J. McCann (1982), "The Impact of Inferential Beliefs on Product Evaluations," Journal of Marketing Research, 19, 324-33.

Johnson, Eric J. and J. Edward Russo (1984), “Product Familiarity and Learning New Information," Journal of Consumer Research, 11 (June), 542-50.

Koufaris, M. (2002), “Applying the Technology Acceptance Model and Flow Theory to Online Consumer Behavior," Information Systems Research, 13 (2), 205-23.

Lohse, Gerald L., Steven Bellman, and Eric J. Johnson (2000), "Consumer Buying Behavior on the Internet: Findings from Panel Data," Journal of Interactive Marketing, 14 (1), 15-29.

Louviere, J. J. (1988), Analyzing Decision Making: Metric Conjoint Analysis. Newbury Park, CA: Sage. and G. Woodworth (1983), "Design and Analysis of Simulated Consumer Choice or Allocation Experiments: An Approach Based on Aggregate Data," Journal of Marketing Research, 20, 350-67. and H. Timmermans (1990), "Stated Preference and Choice Models Applied to Recreation Research: A Review," Leisure Science, 12, 9-32. 
Lynch, John G. and Dan Ariely (1999), "Electronic Shopping for Wine: How Search Costs Affect Consumer Price Sensitivity, Satisfaction with Merchandise, and Retention," working paper, Report No. 99-104, Marketing Science Institute, Cambridge, MA.

, H. Marmorstein, and M. F. Weigold (1988), "Choices from Sets Including Remembered Brands: Use of Recalled Attributes and Prior Overall Evaluations," Journal of Consumer Research, 15, 169-84.

McFadden, D. (1986), "The Choice Theory Approach to Market Research," Marketing Science, 5 (4), 275-97.

Moore,William L. and Madeleine E. Pullman (1999), “Optimal Service Design: Integrating Marketing and Operations Elements for Capacity Decisions," International Journal of Service Industry Management, 10 (2), 125-38.

Moorthy, Sridhar, Brian T. Ratchford, and Debrata Talukdar (1997), "Consumer Information Search Revisited: Theory and Empirical Analysis," Journal of Consumer Research, 23 (March), 263-77.

Palmer, J.W. (2002), “Web Site Usability, Design, and Performance Metrics,” Information Systems Research, 13 (2), 151-67.

Parasuraman, A. (1997), "Reflections on Gaining Competitive Advantage through Customer Value," Journal of the Academy of Marketing Science, 25 (2), 154-61.

Park, C. Whan, David L. Mothersbaugh, and Lawrence Feick (1994), "Consumer Knowledge Assessment," Journal of Consumer Research, 21 (June), 71-82.

Peppers, Don, Martha Rogers, and Bob Dorf (1999), "Is Your Company Ready for One-to-One Marketing?" Harvard Business Review, 77 (January/February), 151-60.

Ratchford, Brian T. (1982), "Cost-Benefit Models of Explaining Consumer Choice and Information-Searching Behavior," Management Science, 28, 197-212.

Rust, R. T. and K. N. Lemon (2001), "E-Service and the Consumer," International Journal of Electronic Commerce, 5 (3), 85-101.

— - , and V. A. Zeithaml (2001), “Driving Consumer Equity: Linking Consumer Lifetime Value to Strategic Marketing Decisions," Research Report No. 01-108, Marketing Science Institute, Cambridge, MA.

Shankar, Venkatesh, Arvind Rangaswamy, and Michael Pusateri (1999), "The Impact of Internet Marketing on Price Sensitivity," working paper, Penn State e-Business Research Center, State College, PA.

Shapiro, Carl and Hal R. Varian (1999), Information Rules: A Strategic Guide to the Network Economy. Boston: Harvard Business School Press. 
Sinha, Indrajit (2000), "Cost Transparency: The Net's Real Threat to Prices and Brands," Harvard Business Review, 78 (March/April), 43-50.

Swait, J. and Jordan J. Louviere (1993), "The Role of the Scale Parameter in the Estimation and Comparison of Multinomial Logit Models," Journal of Marketing Research, 30, 305-14.

Timmons, Heather (2000), “Online Banks Can't Go It Alone,” Business Week, July 31, 87.

Torkzadeh, G. and G. Dhillon (2002), "Measuring Factors That Influence the Success of Internet Commerce," Information Systems Research, 13 (2), 187-204.

Verma, R., G. Plaschka, and J. J. Louviere (2002), “Understanding Customer Choices: A Key to Successful Service Management," Cornell Quarterly, 43 (6), 15-24.

— , G. M. Thompson, and J. J. Louviere (1999), "Configuring Service Operations Based on Customer Needs and Preferences," Journal of Service Research, 1 (3), 262-74.

- - , W. L. Moore, and J. J. Louviere (2001), “Effective Design of Products/Services: An Approach Based on Integration of Marketing and Operations Management Decisions," Decision Sciences, 32 (1), 165-93.

"The Web's Top Sellers," (2000), The Industry Standard, August 7, 152. Woodruff, R. B. (1997), "Customer Value: The Next Source for Competitive Advantage," Journal of the Academy of Marketing Science, 25 (2), 139-53.

Xue, M., P. T. Harker, and G. R. Heim (2000), “Website Efficiency, Customer Satisfaction and Customer Loyalty: A Customer Value Driven Perspective," working paper, University of Pennsylvania, Philadelphia.

\section{Author Bios}

Zafar lqbal is an assistant professor of marketing at DePaul University. He earned his Ph.D. from the University of Pittsburgh in 1999. His research focuses on the areas of new product and service development, managerial decision making, developing practical tools for marketers, and gray markets. He has published various articles in the Journal of Personal Selling and Sales Management and the Journal of Risk and Insurance.

Rohit Verma is an associate professor of operations management in the David Eccles School of Business at the University of Utah. His research interests include product/service design, operations strategy, choice modeling and operations/marketing interrelated issues. His research has appeared in Decision Sciences, the Journal of Operations Management, the Journal of Product Innovation Management, the Journal of Service Research, Omega, Production and Operations Management, and other journals. He received the "Skinner Award for Early Career Research Accomplishments" from the Production and Operations Management Society in April 2001. He is also one of the first recipients of the "Sprit of Inquiry Award," the highest honor for scholarly activities within DePaul University, where he taught during 1995 to 2001. 
Roger Baran is an associate professor of marketing and director, Asian and Middle Eastern Graduate Programs at DePaul University. He earned his Ph.D. from the University of Chicago in 1980. He has published various articles in the Journal of Euromarketing and Management Education for Countries in Transition. 